\title{
The Combination Cyclophosphamide with Radiation Increases Tumour Cure in Ehrlich Ascites Carcinoma Bearing Mice as well as DNA Damage in the Normal Mice Bone Marrow Exposed to Different Doses of $\Gamma$-Radiation
}

\author{
Ganesh Chandra Jagetia ${ }^{1 *}$ and Manjeshwar Shrinath Baliga ${ }^{2}$ \\ ${ }^{1}$ Maharana Pratap Colony, India \\ ${ }^{2}$ Father Muller Research Centre, India \\ Submission: May 03, 2018; Published: July 03, 2018 \\ *Corresponding author: Ganesh Chandra Jagetia, Maharana Pratap Colony, Sector-13, Hiran Magri, Udaipur-313002, India, Email: gc.jagetia@ \\ gmail.com
}

\begin{abstract}
Alterations in the radiation-induced micronuclei formation was studied in mice bone marrow treated with $0.5 \mathrm{mg} / \mathrm{kg}$ body weight $\left(1 / 500^{\text {th }}\right.$ of the $\mathrm{LD}_{50}$ ) of cyclophosphamide (CPA) before exposure to 0, 0.5, 1, 2 and 3Gy of $\gamma$-radiation. Irradiation of animals caused a dose dependent elevation in the Micro-nucleated Polychromatic Erythrocytes (MPCE) and Micro nucleated Norm chromatic Erythrocytes (MNCE) in the bone marrow of mice at $24 \mathrm{~h}$ post-irradiation. Treatment of mice with $0.5 \mathrm{mg} / \mathrm{kg}$ CPA elevated the radiation-induced MPCE significantly up to $2 \mathrm{~Gy}$ irradiation and showed a significant decline thereafter when compared to the concurrent sterile physiological saline (SPS) treated irradiated group. The frequency of radiation-induced MNCE also showed a significant elevation after CPA treatment at all exposure doses. In a separate experiment the effect of $0.5 \mathrm{mg} / \mathrm{kg}$ b. wt. CPA was evaluated in combination with radiation in the Ehrlich Ascites Carcinoma bearing mice (EAC). The combination of $0.5 \mathrm{mg} / \mathrm{kg}$ b. wt. of CPA with 1, 2, 4, 6 and 8Gy of irradiation increased both the Median Survival Time (MST) and Average Survival Time (AST) of the EAC bearing mice when compared with the SPS+ irradiation and the maximum effect was observed in mice that received CPA and 8Gy of radiation. Our study demonstrates that the risk of genomic instability and mutagenesis outweighs the benefit accrued in the tumor bearing mice receiving combination of CPA and ionizing radiation.
\end{abstract}

Keywords: Cyclophosphamide; Radiation; Micronuclei; Ehrlich ascites carcinoma; Median survival time; Average survival time; Acute toxicity

\section{Introduction}

Study into the history of chemotherapeutic drugs for cancer treatment reveals that no drug has been advocated and as widely used as Cyclophosphamide for the past sixty years. Cyclophosphamide is a bi-functional alkylating agent and has been reported to give a better therapeutic index than other alkylating agents in animals and the reason for its greater selectivity is due to involvement of a complex metabolic pathway, that causes greater detoxification of the active alkylating species in normal cells such as bone marrow when compared with the tumor cells [1]. The Cyclophosphamide has been used to treat more susceptible neoplasm such as breast cancer, Burkitt's lymphomas, multiple myeloma and chronic leukemias [13]. Cyclophosphamide is also a potent immunosuppressive agent and is useful in a variety of nonmalignant diseases like nephrotic syndrome, rheumatoid arthritis, neuromyelitis optica, interstitial lung disease, systemic Sclerosis, cicatricial, pemphigoid (also called pemphigoid mucous membrane), juvenile dermatomyositis, lupus vasculopathy, systemic vasculitis,myasthenia gravis, multiple sclerosis, scleroderma, autoimmune hemolytic anemia and other autoimmune diseases [4-6]. It has also received considerable attention for the control of organ rejection after transplantation $[7,8]$.

Chemotherapeutic drugs used in the treatment of cancer usually damage DNA, which is expressed as DNA strand breakage, chromosome breaks and loss or gain of chromosomes (aneuploidy). The DNA damaging agents have been reported to cause phenotypic abnormalities like spontaneous abortion, congenital malformations and malignant transformations [9-12]. Cyclophosphamide is frequently combined with the other chemotherapeutic drugs in the treatment of refractory and resistant tumors in combination with other neo-plastic drugs (like doxorubicin, methotrexate, fluorouracil) for the treatment of malignant lymphomas, non-Hodgkin's lymphoma, Hodgkin's lymphoma, adult acute leukemia, refractory breast 
cancers, endometrial carcinomas, small cell carcinoma of the lung, multiple myeloma, sarcomas, advanced mycosis fungoides, neuroblastoma, retinoblastoma, ovarian carcinoma, bronchogenic carcinoma and other types of resistant cancer $[1,13]$.

In several instances it is also combined with irradiation to achieve better therapeutic gains especially, to eradicate the chances of metastasis and enhance the cytotoxicity of radiation [13-16]. The cyclophosphamide therapy in patients either alone or along with radiotherapy has been reported to induce second malignancies [16-18]. The Cyclophosphamide induces several adverse effects in the patient receiving cyclophosphamide therapy including oxidative stress, pneumonitis, genotoxicity, hepatotoxicity, severe hyponatremia, heartfailure and pulmonary fibrosis $[6,19,20]$. The patients receiving combination treatment are at an increased risk of developing secondary neoplasia in comparison to those receiving a single treatment modality. The UNSCEAR report [21] has rightfully emphasized that the mode of interaction between chemicals and radiation should be tested in diverse biological systems.

The use of mice models to test such interactions is widely accepted since it helps to understand the deleterious effects inflicted by the combination treatments. In combination therapy usually, low doses of chemotherapeutic agents and radiation are used to avoid or minimize the adverse toxic side effects of the combination treatment. Therefore, the aim of the present study was to evaluate the therapeutic benefit and the adverse effect of very low dose of Cyclophosphamide $\left(0.5 \mathrm{mg} / \mathrm{kg}\right.$ b. wt. i.e. $1 / 500^{\text {th }}$ of the $\mathrm{LD}_{50}$ ) in the Swiss albino mice.

\section{Materials and Methods}

\section{Animal care and handling}

The animal care and handling were done according to the guidelines set by the World Health Organization, Geneva, Switzerland and the INSA (Indian National Science Academy, New Delhi, India). Ten to twelve weeks old male Swiss albino mice weighing 30 to $36 \mathrm{~g}$ were selected from an inbred colony maintained under the controlled conditions of temperature $\left(23 \pm 2{ }^{\circ} \mathrm{C}\right)$, humidity $(50 \pm 5 \%)$ and light (14 and $10 \mathrm{~h}$ of light and dark, respectively). The animals had free access to sterile food and water. Four animals were housed in a polypropylene cage containing sterile paddy husk (procured locally) as bedding throughout the experiment. The study was cleared by the institutional animal ethical committee of the Manipal University, Manipal, India, where the study was conducted.

\section{Preparation of drug}

Cyclophosphamide CPA (Endoxan), was procured from Khandewal Laboratories, Mumbai, India and was prepared in sterile physiological saline (SPS).

\section{Mode of administration}

The animals were administered with $0.01 \mathrm{ml} / \mathrm{g}$ body weight either SPS or CPA intraperitoneally.

\section{Acute toxicity of CPA}

The acute toxicity of CPA was determined according to standard protocol [22,23]. Briefly, the animals (non-tumor bearing) were allowed to fast by withdrawing the food and water for $18 \mathrm{~h}$. The fasted animals were divided into several groups of 10 each. Each group of animals was injected with 150, $175,200,225,250,275,300,400$ and $500 \mathrm{mg} / \mathrm{kg}$ body weight of CPA intra-peritoneal. The animals were provided with food and water immediately after the drug administration. Mortality of the animals was observed up to 30 days post drug treatment.

\section{Experimental protocol}

The normal (non-tumor bearing animals) or tumor bearing animals were divided into two groups as follows: SPS+Irradiation: The animals of this group received $0.01 \mathrm{ml} / \mathrm{g}$ body weight of SPS before irradiation. CPA+ Irradiation: The animals of this group received $0.5 \mathrm{mg} / \mathrm{kg}$ body weight of CPA $\left(1 / 50^{\text {oth }}\right.$ of the $\mathrm{LD}_{50}$ dose $)$ before irradiation.

\section{Irradiation}

Forty-five minutes after the administration of SPS or CPA, the prostrate and immobilized animals (achieved by inserting cotton plugs in the restrainer) were whole or hemi-body exposed to ${ }^{60} \mathrm{Co} \gamma$-radiation (Gammatron, Siemens, Germany) in a specially designed well-ventilated acrylic box. A batch of eight animals was irradiated each time at a dose rate of $1 \mathrm{~Gy} / \mathrm{min}$ at a source to animal distance (midpoint) of $60 \mathrm{~cm}$ for micronucleus assay. Whereas a batch of twelve animals were irradiated each time at a dose rate of $2 \mathrm{~Gy} / \mathrm{min}$ at a source to animal distance (midpoint) of $60 \mathrm{~cm}$ for anticancer studies. Immediately after irradiation, the animals were sorted into the individual polypropylene cages.

\section{Micronucleus assay}

A separate experiment was performed to study the effect of Cyclophosphamide in conjunction with radiation, where normal non-tumor bearing mice were divided into two groups as described in the experimental protocol section. The animals were whole body exposed to $0,0.5,1,2$ or $3 G y \gamma$-radiation. The micronuclei were prepared in the bone marrow of mice 24 after irradiation. Briefly, the animals were killed $24 \mathrm{~h}$ post-irradiation and the femora of each animal was removed and freed from muscles and other tissues. The bone marrow was extracted in the minimum essential medium and collected in the centrifuge tubes. The bone marrow was dispersed and centrifuged, the supernatant was discarded and a few drops of fetal calf serum was added into the tubes and thoroughly mixed.

A few drops were placed on to pre-cleaned pre-coded glass micro-slides and smears were drawn. The cells were fixed in absolute methanol and stained with $0.125 \%$ Acridine orange. The micronuclei (pale green) were scored in polychromatic (orange) and normochromatic (khaki) erythrocytes. A total of each 1000 polychromatic and normochromatic erythrocytes were scored from individual animals and a total of 4 animals were used for each radiation dose in each group. 


\section{Radiosensitizing Effect of CPA in Tumor Bearing Mice \\ Tumor model}

Ehrlich ascites carcinoma (EAC) procured from Cancer Research Institute (ACTREC), Mumbai, India was maintained and propagated by intra-peritoneal serial transplantation into female Swiss albino mice in an aseptic environment. No spontaneous regression of EAC tumor was observed throughout the study. The experiments were carried out by injecting $10^{6}$ viable EAC cells intraperitoneally in an aseptic condition into each animal and the day of tumor inoculation was considered as day 0 . Twenty-four hours after the tumor inoculation the animals were divided into two groups as described in the experimental protocol section. The tumor bearing animals were administered with sterile physiological saline or Cyclophosphamide 45 minutes before exposure to different doses of $\gamma$-radiation. The lower half (below rib cage of the tumor bearing animals was exposed to $0,1,2,4,6$ or 8 Gy of $\gamma$ - radiation as described in the irradiation section.

The animals were monitored regularly for the alteration in body weight, signs of toxicity and mortality. The weight of animals was recorded every third day up to 30 days after tumor inoculation in all the groups. A 33\% of drug related deaths or a weight loss of $5 \mathrm{~g}$ per mouse was considered as an index of toxicity. The animal survival was monitored daily up to 120 days, since the survival of animals up to 120 days is roughly equivalent to 5 years survival in man [24]. The tumor response was assessed on the basis of median survival time and tumor free survival. The Median Survival Time (MST), and the Average Survival Time (AST) were calculated from the animals dying within 120 days and those surviving 120 days were excluded from it. The MST AST, IMLS (increase in median life span) and IALS (increase in average life span) were calculated as follows:

MST=First death in the group + last death in the group/2

AST=Sum of death of animals on different days/Number of animals

The increase in median life span (\% IMLS) and the increase in average life span (\% IALS) were calculated as follows: -

IMLS=MST of treated mice - MST of controlX100/ MST of control

IALS=AST of treated mice - AST of control X 100/ AST of control

\section{Statistical Analysis}

Statistical analysis for the micronucleus test was carried out using Mann Whitney ' $U$ ' test and one-way analysis of variance (ANOVA). A p value of $<05$ was considered statistically significant for all the experiments. The daily survival analysis was carried out using Kaplan-Meir's equation while the significance between the treatments was determined using ' $\mathrm{Z}$ ' test for survival studies using the following formula [25]:-

$$
z=\frac{\hat{p}_{1}-\hat{p}_{2}}{\sqrt{\hat{p}(1-\hat{p})\left(1 / n_{1}+1 / n_{2}\right)}}
$$

where $=($ number of successes $) /$ total sample size

\section{Results}

\section{Acute toxicity of CPA}

The administration of 150,175 and $200 \mathrm{mg} / \mathrm{kg}$ body weight of CPA did not induce any mortality during the whole observation period. However, a further increase in the drug dose to $225 \mathrm{mg} /$ $\mathrm{kg}$ body weight caused $20 \%$ reduction in the survival of mice. When the dose of CPA was increased up to $250 \mathrm{mg} / \mathrm{kg}$ body weight the survival of mice declined by $50 \%$, whereas $80 \%$ of the animals died when the drug dose was raised up to $275 \mathrm{mg} /$ $\mathrm{kg}$. All the animals (100\% mortality) died after administration of $300 \mathrm{mg} / \mathrm{kg}$ and thereafter up to a dose of $500 \mathrm{mg} / \mathrm{kg}$ b. wt. CPA, the last dose evaluated.

\section{Effect of CPA on the radiation-induced micronuclei formation}

The results are expressed as micronucleated polychromatic (MPCE) and micronucleated normochromatic erythrocytes (MNCE) per thousand \pm SEM (standard error of the mean) in Table 1 and Figure 1. The exposure of mice to 0.5 to $3 \mathrm{~Gy}$ of $\gamma$ radiation resulted in a dose dependent increase in the MPCE. Treatment of mice with $0.5 \mathrm{mg} / \mathrm{kg}$ CPA further elevated the frequency of MPCE up to 2Gy, whereas a further increase in the irradiation dose caused a significant decline in the MPCE, when compared with the concurrent irradiated group (Figure 1). The frequency of cells bearing one and two micronuclei is shown separately (Table 1). The frequency of one and two MPCE also showed a dose dependent increase (Figure 1). The pretreatment of mice with CPA increased the frequency of one and two MPCE significantly in the CPA+irradiation group at all exposure doses when compared with the concurrent DDW+irradiation group. The frequency of one MPCE declined after 2Gy irradiation in CPA+irradiation groups, whereas that of the two MPCE increased continuously.

Table 1: Alteration in the micronuclei frequency in the bone marrow of mice treated with $0.5 \mathrm{mg} / \mathrm{kg}$ body

\begin{tabular}{|c|c|c|c|c|c|c|c|c|}
\hline Expsoure & \multicolumn{7}{|c|}{ Frequency of Micronucleated Erythrocytes Per 1000 \pm SEM } \\
\hline Dose (Gy) & PCE Bearing One Micronuclei & PCE Bearing & Two Micronuclei & \multicolumn{2}{c|}{ MPCE Total } & \multicolumn{2}{c|}{ NCE Bearing Micronuclei } \\
\hline & SPS+IR & CPA+IR & SPS + IR & CPA+IR & SPS+IR & CPA+IR & SPS+IR & CPA+IR \\
\hline 0 & $2.72 \pm 0.38$ & $8.13 \pm 0.90 \mathrm{c}$ & $0 \pm 0$ & $0.50 \pm 0.17$ & $2.72 \pm 0.38$ & $8.63 \pm 0.86 \mathrm{c}$ & $0.75 \pm 0.03$ & $5.41 \pm 0.86 \mathrm{c}$ \\
\hline 0.5 & $28.96 \pm 1.97$ & $45.84 \pm 3.24 \mathrm{c}$ & $2.44 \pm 0.91$ & $3.41 \pm 0.90$ & $31.41 \pm 1.87$ & $49.25 \pm 4.04 \mathrm{a}$ & $2.69 \pm 0.26$ & $13.18 \pm 2.72 \mathrm{c}$ \\
\hline
\end{tabular}




\begin{tabular}{|c|c|c|c|c|c|c|c|c|}
\hline 1 & $51.88 \pm 1.83$ & $64.36 \pm 1.99 \mathrm{c}$ & $4.11 \pm 0.44$ & $6.50 \pm 0.65 \mathrm{c}$ & $55.99 \pm 1.95$ & $70.86 \pm 2.25 \mathrm{c}$ & $6.30 \pm 0.60$ & $15.17 \pm 1.55 \mathrm{c}$ \\
\hline 2 & $77.13 \pm 6.17$ & $86.50 \pm 3.91 \mathrm{a}$ & $6.71 \pm 1.05$ & $10.50 \pm 1.1 \mathrm{c}$ & $83.83 \pm 5.62$ & $97.00 \pm 4.89 \mathrm{~b}$ & $9.82 \pm 0.60$ & $20.39 \pm 2.94 \mathrm{c}$ \\
\hline 3 & $110.77 \pm 8.24$ & $77.05 \pm 8.00$ & $10.48 \pm 1.07$ & $15.03 \pm 1.31 \mathrm{c}$ & $121.24 \pm 8.07$ & $92.08 \pm 7.24 \mathrm{~b}$ & $11.50 \pm 0.99$ & $21.30 \pm 4.11 \mathrm{c}$ \\
\hline
\end{tabular}

weight of cyclophosphamide before exposure to different doses of radiation.

$a=p<0.02, b: p<0.0002, c: p<0.0001$

PCE: Polychromatic Erythrocytes; NCE: Normochromatic Erythrocytes; SPS: Sterile Physiological Saline; CPA: Cyclophosphamide; IR: Irradiation
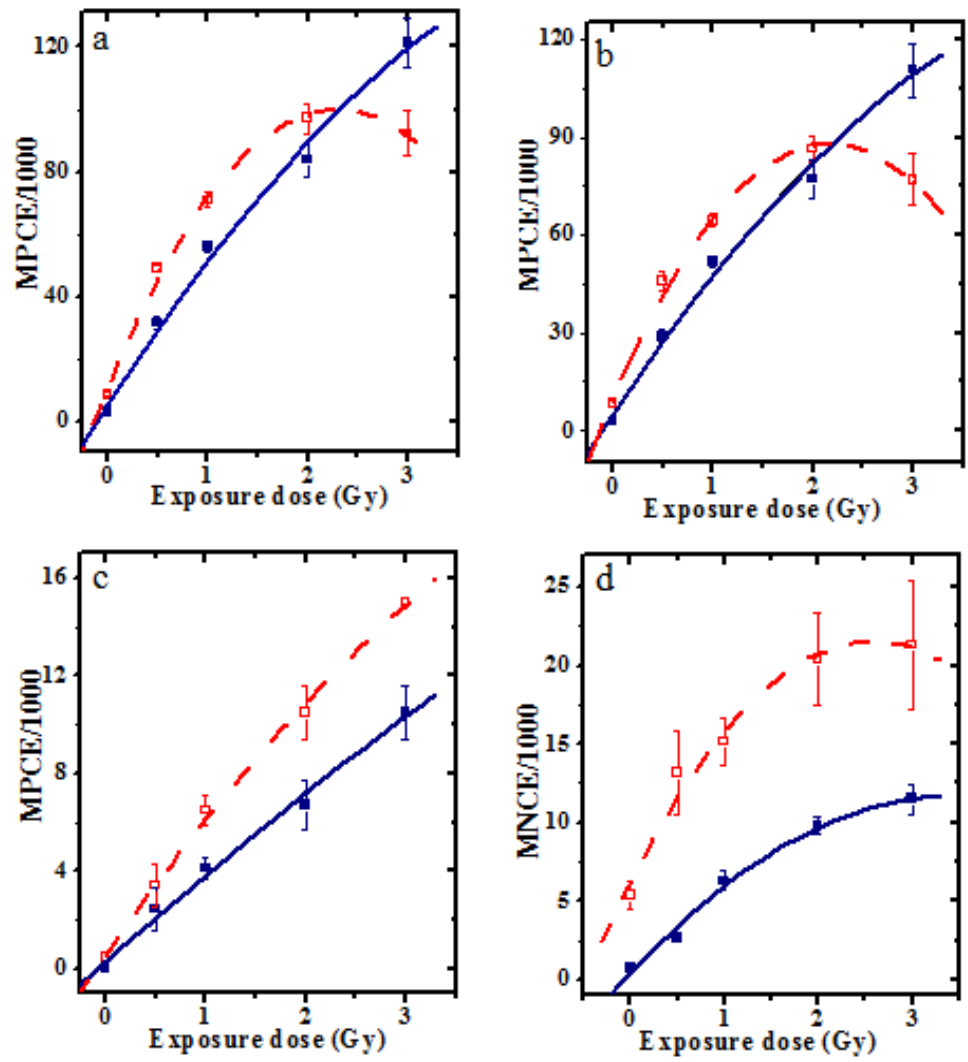

Figure 1: Effect of cyclophosphamide on the induction of micronuclei in the bone marrow of mice exposed to different doses of radiation. Closed symbols SPS + irradiation and open symbols CPA + irradiation. a: Total micronuclei, b: one micronuclei c: two micronuclei and d: micronuclei in NCE.

The irradiation of mice to different doses of $\gamma$-radiation caused a radiation dose dependent elevation in the frequency of MNCE. Treatment of mice with CPA before irradiation further elevated the frequency of MNCE significantly at all exposure doses when compared to the concurrent DDW+irradiation group. This elevation was approximately 2 folds for 1, 2 and 3Gy irradiation, whereas it was 4 folds for 0 . Gy irradiation.

\section{Radiosensitizing effect of CPA in tumor bearing mice}

Tumorized EAC mice did show spontaneous regression as the evident by a constant weight gain due to the tumor cell multiplication and tumor growth of the tumorized mice (Figure 2). The first death of tumorized mice was observed on day 16 and all the tumorized animals of SPS group died by day 18 posttumor inoculation (Figure 3). The Median Survival Time (MST) was found to be 17 in the SPS group, and the average survival time (AST) was 16.8 days (Table 2 and Figure 4).
The exposure of $24 \mathrm{~h}$ old tumorized mice with 1,2,4,6 or $8 \mathrm{~Gy}$ of $\gamma$-radiation retarded the weight gain at all irradiation doses indicating arrest of tumor cell proliferation and growth (Figure 2). The MST was found to be $17,20,21,23$ and 25.5 days, and the AST was 16.6,20.6,21.2,23.2 and 25.6 days after exposure to $1,2,4,6$ or $8 \mathrm{~Gy}$, respectively (Figure 4 and Table 2). The $1 \mathrm{~Gy}$ exposures did not have any effect of MST and AST, whereas the MST and AST increased in a radiation dose dependent manner and the highest rise in MST and AST was detected in the animals that were exposed to $8 \mathrm{~Gy}$ radiation.

The administration of $0.5 \mathrm{mg} / \mathrm{kg}$ b. wt. of CPA resulted in a marginal increase in both MST and AST, which were found to be 18 days (Figure 4 and Table 2). Treatment of EAC mice with CPA before exposure to different doses of $\gamma$-radiation increased the MST and AST in a radiation dose dependent manner. The MST for the combination treatment was found to be 18.5(1Gy), 21(2Gy), 
22.5 (4Gy), 24.5 (6Gy) and 26.5 (8Gy) days, whereas the AST was increased up to 19(1Gy), 21.8(2Gy), 22.7(4Gy), 24.2(6Gy) and 26.9 (8Gy) days. Of all the radiation sensitization regimens, the combination of $0.5 \mathrm{mg} / \mathrm{kg}$ b. wt. of CPA with 8Gy exposures was considered the best as $30 \%$ tumor free survivors could be observed up to 30 days post-irradiation, whereas no such effect was detected at other exposure doses (Table 2 and Figure 3). The elevation in the IMLS and IALS up to 55.9 and $59.7 \%$, respectively (Figure 4 and Table 2). This elevation in the survival was statistically significant $(\mathrm{p}<0.002)$.
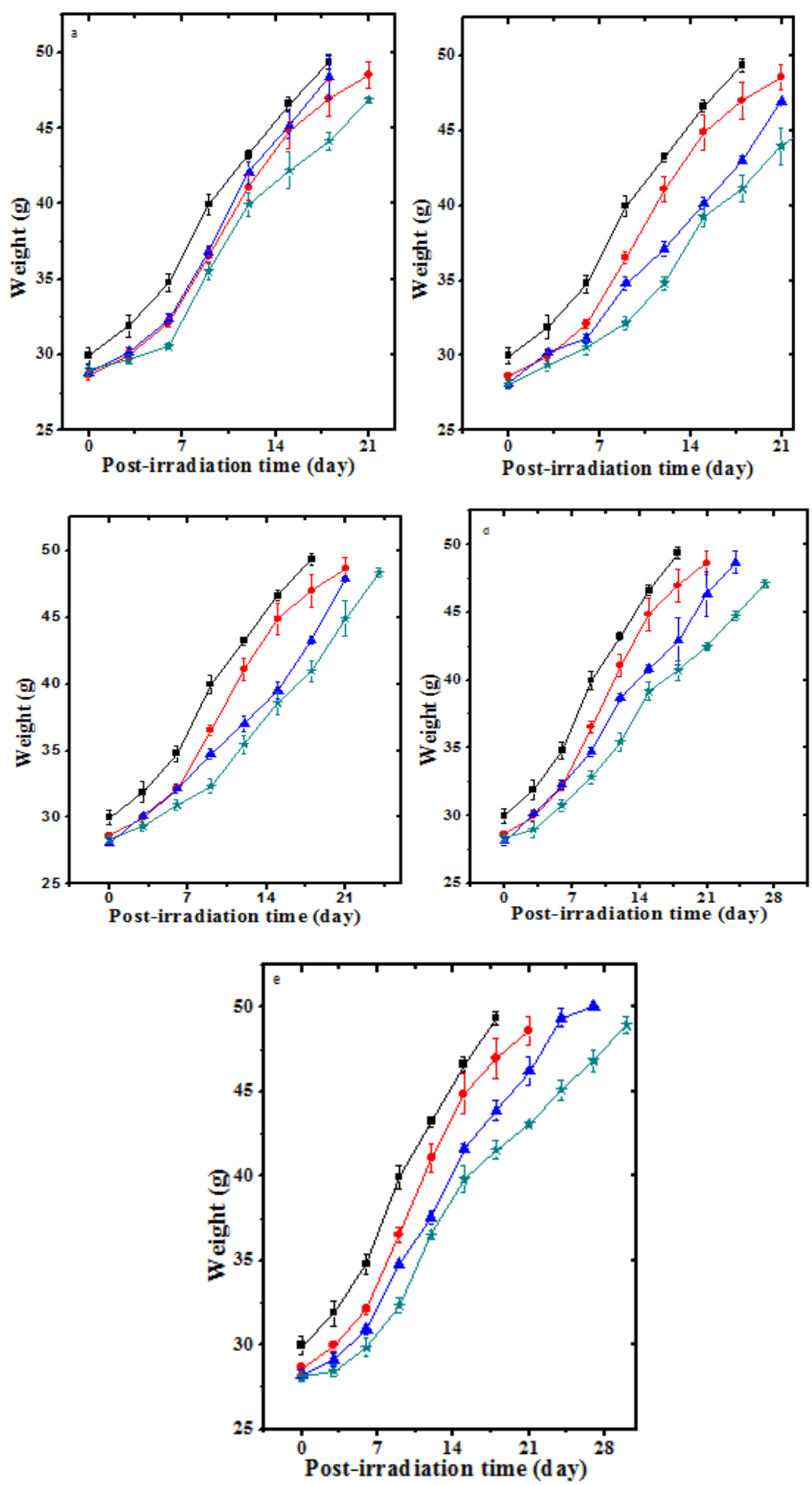

Figure 2: Alteration in the weight of the EAC bearing mice treated with $0.5 \mathrm{mg} / \mathrm{kg} \mathrm{b}$. wt of CPA before exposure to different doses of irradiation. a: 1Gy, b: 2Gy; c: 4Gy; d: 6Gy and e: $8 \mathrm{~Gy}$. Squares: SPS, Circles: CPA alone; Triangles: SPS + irradiation and Stars: CPA + irradiation. 

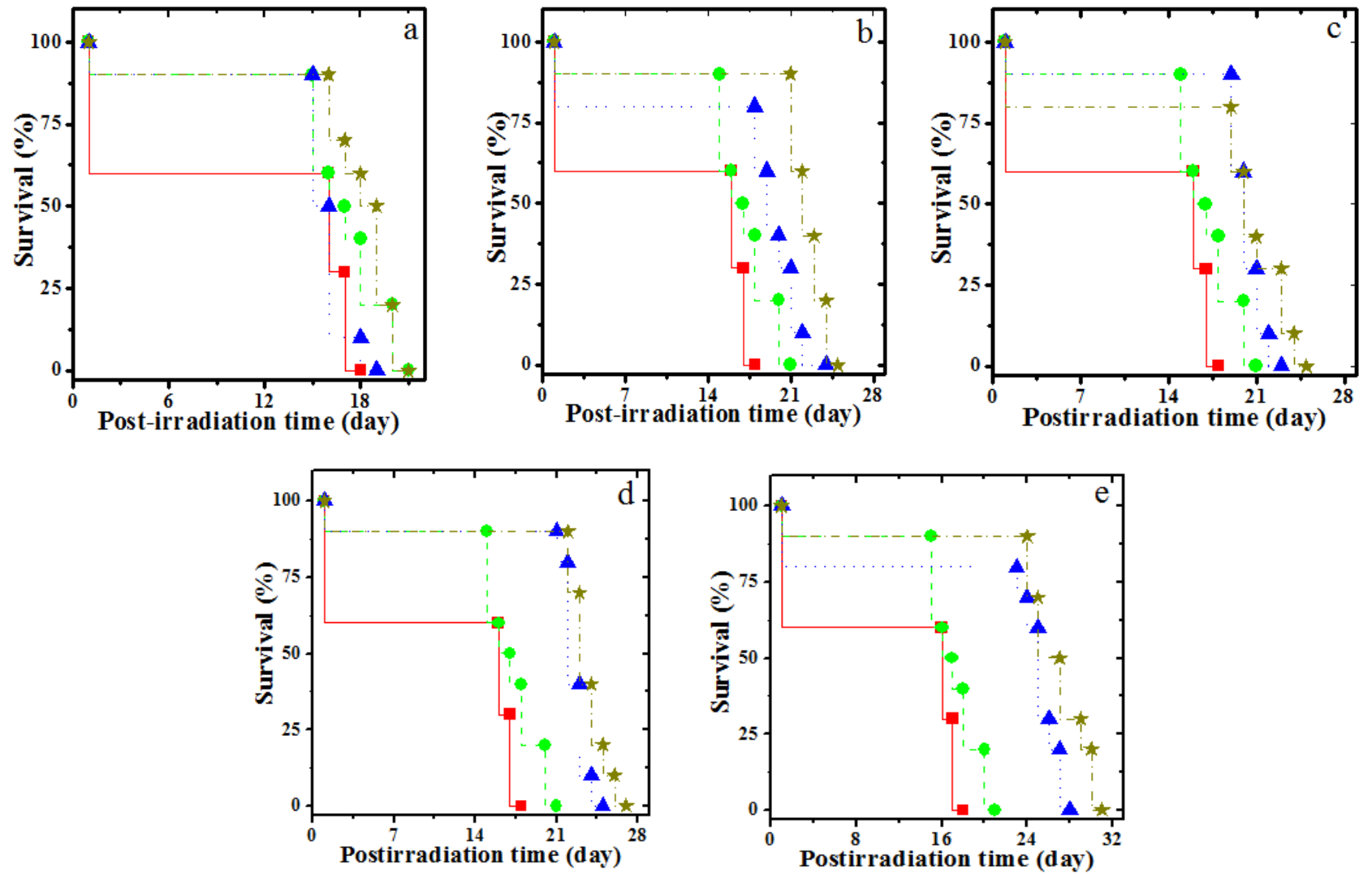

Figure 3: Effect of treatment with $0.5 \mathrm{mg} / \mathrm{kg} \mathrm{b}$. wt of CPA before exposure to different doses of $\mathrm{y}$-irradiation. a: $1 \mathrm{~Gy}$, b: $2 \mathrm{~Gy}$; c: $4 \mathrm{~Gy}$; d: $6 \mathrm{~Gy}$ and e: 8Gy on the survival of the EAC bearing mice. Solid squares: SPS, open squares CPA alone; closed circles: SPS + irradiation and open circles: CPA + irradiation.
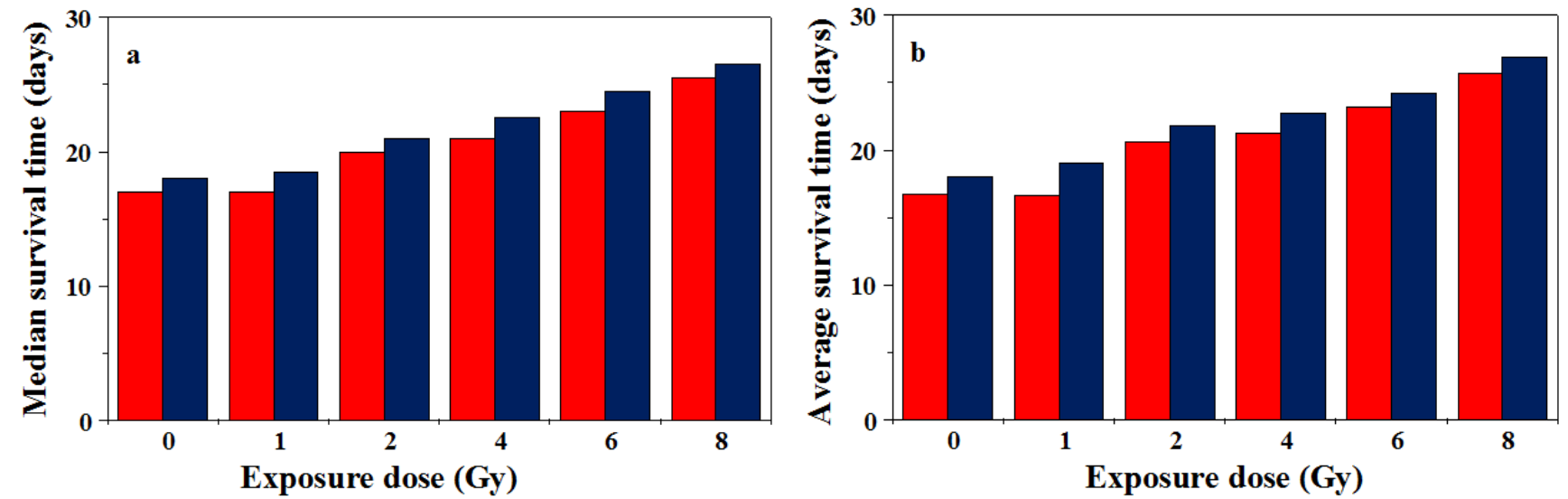

Figure 4: Effect of cyclophosphamide in enhancing the radiation-induced increase in the median survival time (MST) and average survival time (AST) in the EAC bearing mice. a: MST and b: AST. Red bars: SPS + irradiation and Blue bars: CPA + irradiation.

Table 2: Alteration in the survival of tumor bearing mice administered with $0.5 \mathrm{mg} / \mathrm{kg}$ body weight of cyclophosphamide before exposure to different doses of irradiation.

\begin{tabular}{|c|c|c|c|c|c|}
\hline Drug Dose (mg/kg) & MST(Days) & IMLS & AST(Days) & IALS & Percent survival Day 30 \\
\hline SPS+ IR 0 & 17 & - & 16.8 & - & 0 \\
\hline CPA 0.5 + IR 0Gy & 18 & 5.9 & 18 & 7.14 & 0 \\
\hline CPA 000+ IR 1Gy & 17 & - & 16.6 & - & 0 \\
\hline CPA 0.5 + IR 1Gy & 18.5 & 8.82 & 19 & 13.1 & 0 \\
\hline CPA 000+ IR 2Gy & 20 & 17.65 & 20.6 & 2.62 & 0 \\
\hline
\end{tabular}


Current Trends in Biomedical Engineering \& Biosciences

\begin{tabular}{|l|c|c|c|c|c|}
\hline CPA 0.5 + IR 2Gy & 21 & 23.6 & 21.8 & 29.76 & 0 \\
\hline CPA 000+ IR 4Gy & 21 & 23.6 & 21.2 & 26.19 & 0 \\
\hline CPA 0.5 + IR 4GY & 22.5 & 32.36 & 22.7 & 35.12 & 0 \\
\hline CPA 000+ IR 6GY & 23 & 35.3 & 23.3 & 38.7 & 0 \\
\hline CPA 0.5 + IR 6Gy & 24.5 & 44.12 & 24.2 & 44.05 & 0 \\
\hline CPA 000+ IR 8Gy & 25.5 & 50 & 25.6 & 52.38 & $30 a$ \\
\hline CPA 0.5 + IR 8Gy & 26.5 & 55.9 & 26.9 & 59.7 & 3 \\
\hline
\end{tabular}

$a=p<0.002$.

\section{Discussion}

Cyclophosphamide has a wide spectrum of documented clinical use and is often included in combination regimens for the treatment of refractory tumours [6,16,26-28]. The combination of chemotherapy and radiotherapy has been used with a remarkable success, especially in cases, where either therapy alone has proved ineffective. The radiotherapy and chemotherapy are applied concomitantly or alternatively to overcome the higher clinical toxicity, where low doses of both the agents are used. The use of these regimens has resulted in the increased survival of patients receiving the treatment [2931]. However, chemotherapeutic agents and radiation cause DNA damage not only to the malignant cell but also to normal cells. This genomic damage to normal cells is a cause of concern as it causes mutagenesis in the surviving normal cells, which may subsequently acquire neoplastic characters leading to second malignancies in the survivors [32-34]. This damage could be enhanced when both cytotoxic drugs and radiation are combined for therapeutic purposes. This may result in the reduction of the latency period for neoplastic transformation. The combination of chemotherapy and radiotherapy has been reported to increase the risk of secondary tumours in humans and reduce the latency period $[34,35]$. This indicates that there is a need to study the adverse effect of combination treatment in normal tissues in addition to the tumour tissues that are subjected to combination treatment. Therefore, the present investigation was carried out to study the therapeutic benefit and the genotoxic effects of the combination of $0.5 \mathrm{mg} / \mathrm{kg}$ body weight of CPA with radiation in mice.

The combination of CPA with radiation increased the survival and quality of life in EAC bearing mice when compared with the non-drug treated irradiated mice. Similar observations have been reported earlier on the sarcoma I (SaI) cells grown in A/Jax mice and C3H mice mammary carcinoma [36,37]. The treatment of Kunming mice bearing sarcoma-180 with 300mg/ $\mathrm{kg}$ cyclophosphamide after low dose irradiation has been found to markedly regress the tumor [38]. Low dose radiation and Cyclophosphamide has been reported to increase survival in elderly patient up to 10 years [39]. The agents which inhibit the DNA synthesis and cell cycle progression like Adriamycin, teniposide, etoposide, carmustine, cyclophosphamide, cisplatin, carboplatin, hydroxyurea, methotrexate, 5 fluorouracil, AZT,
$\mathrm{ACV}$, valinomycin, bleomycin have been reported to enhance the radiation effects in vitro and in vivo [40-49].

Micronucleus assay has been used to predict the chromosomal instability and carcinogenicity in various experimental models [50-52]. The irradiation of mice to different doses of gamma radiation not only increased the $\mathrm{MN}$ with one $\mathrm{MN}$ but also the cells bearing $2 \mathrm{MN}$ in a dose dependent manner in the normal mice bone marrow and CPA pre-treatment further increased their frequency significantly. Irradiation has been reported to increase the frequency of cells with 1 and $2 \mathrm{MN}$ in mice and various cultured cell lines $[47,52-58]$. The induction of multiple micronuclei in a cell indicates to the multiply sites of irreparable damage suffered by the cell genome, which is subsequently expressed as micronuclei once the cell undergoes division $[59,60]$. As a result of loss of large part of the genome, these cells may not be able to survive long.

However, this may not be the case with the cells bearing one $\mathrm{MN}$, where the probability of adaptation of cells to survive with the deletion of a small part of genome is higher when compared with those cells that have lost a sizeable part of genome in the form of multiple micronuclei. The continued survival and replication of these mutated cells may result in the development of neoplasia in due course of time. Therefore, the cells, which have suffered less damage to their genome, may be more prone to the induction of mutagenesis and carcinogenesis than the cells, which have suffered extensive damage in their genome in the form of multiple micronuclei. Because of the heavy damage to their genome, the cells with multiple MN will not be able to divide and will be relegated from the system without any consequence. The genomic instability observed after the treatment of mice with CPA before irradiation indicates to the increased probability of mutagenesis and carcinogenesis.

The frequency of MN increased up to 2 Gee in CPA+irradiation group and declined thereafter. A similar effect has been reported in mice bone marrow treated with vinblastine before irradiation [61]. The treatment of human lymphocytes with vincristine before exposure to different doses of $\gamma$-radiation also showed an increase in the micronuclei formation up to $1 \mathrm{Gee}$ and declined thereafter [62]. The decline in MN after 2Gy irradiation in the CPA pre-treated group may be owing to the increase in the clastogenic and aneugenic effects of radiation by CPA, that would 
have resulted into the failure of cell division of the affected cells and consequently, such cells may not be able to express micronuclei. Since a cell division is required after any treatment for micronuclei to appear in the daughter cells [63]. In addition to acting as a useful antineoplastic drug, the cyclophosphamide also acts as an immunosuppressive agent and is useful in the treatment of nephritic syndrome, rheumatoid arthritis and other autoimmune diseases and also in the prevention of the graft versus host reaction in the organ transplantation $[3,4,6,13]$. Therefore, the decrease in the micronuclei in the combination treatment at above $2 \mathrm{~Gy}$ may also be due to the immunosuppressive effects of the CPA in conjunction with $\gamma$-irradiation.

Cyclophosphamide is an alkylating agent that get metabolically activated by the action of cytochrome P450 2B6 (CYP2B6) monooxygenase to to form DNA-reactive metabolites, phosphoramide mustard andnornitrogen mustard. The nornitrogen mustard for DNA adducts and cross-linking of DNA strands leading to cell death [64]. However, the cell continues to synthesize other cell constituents, such as RNA and protein leading to an imbalance in the cell functioning and death of the cell [13]. CPA alone has been reported to induce a wide spectrum of chromosomal aberrations in different study systems [19,6567].

The increased formation of MN in combination treatment may be owing to the increase in formation of cyclophosphamide induced DNA adducts, which would have been converted into DNA double strand breaks and chromosome breaks that may have become micronuclei in the cells undergoing at least one cell division. The loss of whole chromosome after CPA. The irradiation would have further increased the FREQUENCY of micronuclei. This may be the reason for the elevation of MN in CPA+irradiation group when compared to the SPS + irradiation group. Similar observations have been reported for the combined treatment of $25 \mathrm{mg} / \mathrm{kg}$ body weight of CPA with X- ray $[68,69]$. However, the significance of our study lies in the fact that the dose of CPA used is extremely low $\left(1 / 500^{\text {th }}\right.$ of the $\left.\mathrm{LD}_{50}\right)$ and even the healthcare workers when administering the drug can encounter such a low dose.

The exact mechanism of action of CPA in conjunction in the present study is not known. However, the cell killing effect seems to be due to induction of DNA damage in the form of micronuclei. This DNA damage may have been responsible for effective cells kill. The CPA is known to induce DNA adducts by the action of cytochrome P450 and DNA crosslinks [64]. The DNA crosslink inhibit DNA repair causing cytotoxicity in the cancer cells [70]. The cyclophosphamide kills tumour cells by triggering oxidative stress induced by the suppression of $\mathrm{Nrf} 2$ transactivation. It may have also inhibited the activation of NF- $\mathrm{KB}$ and COX -II to exert cell killing and DNA damaging effect in the present study.

\section{Conclusion}

The treatment of mice with cyclophosphamide before irradiation resulted in the increased formation of micronuclei I the mice bone marrow and killed effectively the Ehrlich as cites tumour cells in the tumour bearing mice. The cell killing effect may be due to the ability of CPA to inflict DNA damage. The cyclophosphamide triggers the oxidative stress, formation of DNA adducts and DNA cross linking causing reduced RNA and protein synthesis. At molecular level CPA may have inhibited the transactivation of NF- $\mathrm{BB}, \mathrm{COX}-\mathrm{II}$ and Nrf2 that may have been responsible for increased DNA damage and cell kill. However, the present study also indicates that the combination of CPA treatment with $\gamma$-radiation is associated with greater risk of clastogenesis, mutagenesis in the normal cells than the therapeutic benefit. These mutagenic effects may induce treatment related secondary tumours in the survivors.

\section{Acknowledgement}

We are thankful to Dr. Vidyasagar, Professor and Head, and Dr. J.Velmurugan, Dept. of Radiotherapy and Oncology, Kasturba Medical College Hospital, Manipal, India for providing the necessary irradiation facilities and for dosimetric calculations respectively.

\section{References}

1. Colvin OM (1999) An overview of cyclophosphamide development and clinical applications. Curr Pharmaceut Design 5(8): 555-560.

2. Emadi A, Jones RJ, Brodsky RA (2009) Cyclophosphamide and cancer: golden anniversary. Nature reviews Clinical oncology 6(11): 638-647.

3. MadondoMT, Quinn M,Plebanski M(2016)Low dosecyclophosphamide: mechanisms of T cell modulation. Cancer treatment reviews 42: 3-9.

4. DeZern AE, Styler MJ, Drachman DB, Hummers LK, Jones RJ, et al. (2013) Repeated treatment with high dose cyclophosphamide for severe autoimmune diseases. Am J Blood Res 3(1): 84-90.

5. Blank N, Lisenko K, Pavel P, Bruckner T, Ho AD, et al. (2016) Low-dose cyclophosphamide effectively mobilizes peripheral blood stem cells in patients with autoimmune disease. European journal of haematology 97(1): 78-82.

6. Teles KA, Medeiros Souza P, Lima FA, Araújo BG, Lima RA (2017) Cyclophosphamide administration routine in autoimmune rheumatic diseases: a review. Revista Brasileira de Reumatologia 57(6): 596-604.

7. Starzl TE, Putnam CW, Halgrimson CG, Schroter GT, Martineau G, et al. Cyclophosphamide and whole organ transplantation in human beings. Surgery Gynecol Obstet 133(6): 981-991.

8. Fernandes JF, Bonfim C, Kerbauy FR, Rodrigues M, Esteves I, et al. (2018) Haploidentical bone marrow transplantation with posttransplant cyclophosphamide for patients with X-linked adrenoleukodystrophy: a suitable choice in an urgent situation. Bone marrow transplantation 53(4): 392-399.

9. Hanahan D, Weinberg RA (2000) The hallmarks of cancer. Cell 100(1): $57-70$.

10. Gilmore L (2009) Rare chromosome disorders and their developmental consequences. Intellectual Disability Australasia 30(4): 3-7.

11. Munné S (2006) Chromosome abnormalities and their relationship to morphology and development of human embryos. Reproductive biomedicine online 12(2): 234-253.

12. Woods D, Turchi JJ (2013) Chemotherapy induced DNA damage response: convergence of drugs and pathways. Cancer biology \& therapy 14(5): 379-389. 
13. DeVita VT, Chu E (2008) A history of cancer chemotherapy. Cancer Res 68(21): 8643-8653

14. Vietti TJ, Sullivan MP, Haggard ME, Holcomb TM, Berry DH, (1970) Cyclophosphamide and radiation therapy in metastatic Wilm's tumor. Cancer 25: 12-20.

15. Dorr RT, Fritz WL (1980) Cyclophosphamide. In: Cancer chemotherapy handbook. Elsevier/North-Holland Inc, New York, US, pp. 685-691.

16. Xu Y, Wang H, Zhou S, Yu M, Wang X, et al. (2013) Risk of second malignant neoplasms after cyclophosphamide-based chemotherapy with or without radiotherapy for non-Hodgkin lymphoma. Leukem Lymphom 54(7): 1396-1404.

17. Van den Brand JA, van Dijk PR, Hofstra JM, Wetzels JF (2014) Cancer risk after cyclophosphamide treatment in idiopathic membranous nephropathy. Clinical Journal of the Am Soc Nephrol 9(6): 1066-1073.

18. Faurschou M, Mellemkjaer L, Voss A, Keller KK, Hansen IT, et al. (2015) Prolonged risk of specific malignancies following cyclophosphamide therapy among patients with granulomatosis with polyangiitis. Rheumatology 54(8): 1345-1350.

19. Anderson D, Bishop JB, Garner RC, Ostrosky Wegman P, Selby PB (1995) Cyclophosphamide: review of its mutagenicity for an assessment of potential germ cell risks. Mutat Res 330(1-2): 115-181.

20. Ochoa R, Bejarano PA, Glück S, Montero AJ (2012) Pneumonitis and pulmonary fibrosis in a patient receiving adjuvant docetaxel and cyclophosphamide for stage 3 breast cancer: A case report and literature review. J Med Case Rep 30: 413-419.

21. UNSCEAR report (1982) Ionizing radiation sources and biological effects. United Nations, New York, USA, pp. 727-765.

22. Prieur DJ, Young DM, Davis RD, Cooney DA, Homan ER, et al. (1973) Procedures for preclinical toxicologic evaluation of cancer chemotherapeutic agents, protocols of the laboratory of toxicology. Cancer Chemother Rep 4(1): 1-28.

23. Ghosh MN (1984) Toxicity studies. In: Ghosh MN (Ed.), Fundamentals of Experimental Pharmacology, Scientific Book Agency, Calcutta, India, pp.153-158.

24. Nias AHW (1990) Radiation biology. In: Sikora K, Halnan KE (Eds.) Treatment of cancer. Chapman and Hall Medical, London, USA, pp. 53-75.

25. Abramowitz M, Stegun IA (1972) Handbook of Mathematical Functions. Dover Publications, Library of Congress Catalog, New York, UK, p. 925.

26. Samaritani R, Corrado G, Vizza E, Sbiroli C (2007) Cyclophosphamide metronomic chemotherapy for palliative treatment of a young patient with advanced epithelial ovarian cancer. BMC CANCER 7(1): 65.

27. Chu MM, Ma Y, Tse KY, Chan KK, Ngan HY (2015) Cyclophosphamide, hydroxyurea, actinomycin D, methotrexate, and vincristine in the treatment of gestational trophoblastic neoplasia. Int J Gynecol Cancer 25(3): 498-503

28. Nawa Nishigaki M, Kobayashi R, Suzuki A, Hirose C, Matsuoka R, et al. (2018) Control of Nausea and Vomiting in Patients Receiving Anthracycline/Cyclophosphamide Chemotherapy for Breast Cancer. Anticancer Res 38(2): 877-884

29. Fassnacht M, Terzolo M, Allolio B, Baudin E, Haak H, et al. (2012) Combination chemotherapy in advanced adrenocortical carcinoma. New Engl J Med 366(23): 2189-2197.

30. Yardley DA (2013) Drug resistance and the role of combination chemotherapy in improving patient outcomes. Int J Breast Cancer p. 15.

31. Tomasello G, Ghidini M, Barni S, Passalacqua R, Petrelli F (2017) Overview of different available chemotherapy regimens combined with radiotherapy for the neoadjuvant and definitive treatment of esophageal cancer. Expert Rev Clin Pharmacol 10(6): 649-660.

32. Dertinger SD, Avlasevich SL, Torous DK, Bemis JC, Phonethepswath $\mathrm{S}$, et al. (2014) Persistence of cisplatin-induced mutagenicity in hematopoietic stem cells: implications for secondary cancer risk following chemotherapy. Toxicol Sci 140(2): 307-314.

33. Kamran SC, Berrington de Gonzalez A, Ng A, Haas Kogan D, Viswanathan AN (2016) Therapeutic radiation and the potential risk of second malignancies. Cancer 122(12): 1809-1821.

34. Manem VS, Grassberger C, Paganetti H (2017) Predicting organ-specific risk interactions between radiation and chemotherapy in secondary cancer survivors. Cancers 9(9): 119.

35. Zhang AY, Judson I, Benson C, Wunder JS, Ray Coquard I, et al. (2017) Chemotherapy with radiotherapy influences time-to-development of radiation-induced sarcomas: a multicenter study. Brit J Cancer 117(3): 326-331.

36.Zachariae C, Overgaard J (1986) Interactions of radiation, cyclophosphamide and nimorazole in a $\mathrm{C} 3 \mathrm{H}$ mammary carcinoma in vivo. Int J Radiat Oncol Biol Phys 12(8): 1445-1448.

37. Anderson RE, Williams WL, Tokuda S (1987) The effects of cyclophosphamide and irradiation singly and in combination upon SaI growth in A/J mice. Am J Pathol 127(2): 373-379.

38. Yu HS, Xue HW, Guo CB, Song AQ Shen FZ, et al. (2007) Low dose radiation increased the therapeutic efficacy of cyclophosphamide on S180 sarcoma bearing mice. J Radiat Res 48(4): 281-288.

39. Watanabe Y, Ogo E, Kaida H, Suzuki G, Eto H, et al. (2011) Treatment with low-dose cyclophosphamide and radiation therapy for advanced non-small lung cancer in elderly patient. Gan to Kagaku Ryoho. Cancer Chemother 38(9): 1503-1505.

40. Urano M, Ando K, Koike S, Ohara K, Nesumi N (1976) Combined use of bleomycin in radiotherapy of a mouse mammary carcinoma. Gann 67(2): 157-163.

41. Mattern MR, Mong SM, Bartus HF, Mirabelli CK, Crooke ST, et al. (1987) Relationship between the intracellular effects of camptothecin and the inhibition of DNA topoisomerase I in cultured L1210 cells. Cancer Res 47: 1793-1798.

42. Hill BT (1983) Preclinical screening for drugs effective against 5-fluorouracil-resistant cells with a murine L5178Y cell line in vitro. J Natl Cancer Inst 71: 335-340.

43. Grau C, Overgaard J (1992) Effect of etoposide, carmustine, vincristine, 5-fluorouracil, or methotrexate on radiobiologically oxic and hypoxic cells in a $\mathrm{C} 3 \mathrm{H}$ mouse mammary carcinoma in situ. Cancer Chemother Pharmacol 30: 277-280.

44. Aratani Y, Yoshiga K, Mizuuchi H, Jo A, Tanimoto K, et al. (1997) Antitumor effect of carboplatin combined with radiation on tumors in mice. Anticancer Res 17: 2535-2538.

45. Severin E, Hagenhoff B (1988) Synchronization of tumor cells with 5 -fluorouracil plus uracil and with vinblastine and irradiation of the synchronized cultures, A contribution to combined radio-chemotherapy. Strahlenther Onkol 164: 165-172.

46. Sougawa M, Yoshii G, Tanaka Y (1986) Radiosensitization effects of nucleoside analogs. Nippon Igaku Hoshasen Gakkai Zasshi 46(12): 1415-1420.

47. Jagetia GC, Nayak V (2000) Effect of doxorubicin on cell survival and micronuclei formation in HeLa cells exposed to different doses of $\gamma$-radiation. Strahlenther Onkol 176(9): 422-428.

48. Jagetia GC, Aruna R (2000) Effect of acyclovir on the radiation-induced micronuclei-induction and cell death. Mutat Res 469: 9-21.

49. Jagetia GC, Aruna R (2003) Correlation of micronuclei induction 
with the cell survival in HeLa cells treated with a base analogue, azidothymidine (AZT) before exposure to different doses of $\gamma$-radiation. Toxicol Lett 139(1): 33-43.

50. Eastmond DA, Hartwig A, Anderson D, Anwar WA, Cimino MC, et al (2009) Mutagenicity testing for chemical risk assessment: update of the WHO/IPCS Harmonized Scheme. Mutagenesis 24(4): 341-349.

51. Kang SH, Kwon JY, Lee JK, Seo YR (2013) Recent advances in In vivo genotoxicity testing: prediction of carcinogenic potential using comet and micronucleus assay in animal models. J Cancer Prevent 18(4): 277-288.

52. Jagetia GC, Adiga SK (1997) Correlation between micronuclei-induction and cell survival in V79 cells exposed to paclitaxel (taxol) in conjunction with radiation. Mutat Res 337(1): 105-113

53. Jagetia GC, Adiga SK (2000) Correlation between cell survival and micronuclei formation in V79 cells treated with vindesine before exposure to different doses of $\boldsymbol{\gamma}$-radiation. Mutat Res 448(1): 57-68.

54. Belyakov OV, Prise KM, Trott KR, Michael BD (1999) Delayed lethality, apoptosis and micronucleus formation in human fibroblasts irradiated with X-rays or $\alpha$-particles. Int J Radiat Biol 75(8): 985-993.

55. Jagetia GC, Reddy TK (2002) The grapefruit flavanone naringin protects against the radiation-induced genomic instability in the mice bone marrow: a micronucleus study. Mutat Res 519(1-2): 37-48.

56. Jagetia GC, Venkatesh P (2007) Inhibition of radiation-induced clastogenicity by Aegle marmelos (L) Correa in mice bone marrow exposed to different doses of g-radiation. Hum Exp Toxicol 26(2): 111124

57. Jagetia GC, Venkatesha VA, Rohituka, Aphanamixis Polystachya R (2017) Parker augments the radiosensitivity of HeLa cells exposed to different doses of $\gamma$-radiation: correlation of DNA damage and clonogenicity. J Altern Med Res 3(10): 120.

58. Jagetia GC, Venkatesh PB, Marmelos A (2015) Correa, an Indian medicinal plant protects V79 cells against the genotoxic effect of doxorubicin. Int J Genet Mol Biol 7(5): 32-46.

59. Dikomey E, Borgmann K, Köcher S, Kriegs M, Mansour W, et al. (2016) Radiation DNA damage and use in cancer/therapeutics-translation of radiation modifiers. DNA Repair in Cancer Therapy, pp. 329-352.
60. Jagetia GC, Jacob PS (1994) The influence of treatment of vinblastine on the formation of radiation-induced micronuclei in mouse bone marrow. Hereditas 120(1): 51-59.

61. Jagetia GC, Baliga MS (2002) Vincristine increases the genomic instability in irradiated cultured human peripheral blood lymphocytes. Toxicol lett 126(3): 179-186.

62. Heddle J (1973) A rapid in vivo test for chromosomal damage. Mutat Res 18(2): 187-190.

63. Malayappan B, Johnson LA, Nie B, Panchal D, Matter B, et al. (2010) Quantitative high-performance liquid chromatography- electrospray ionization tandem mass spectrometry analysis of bis-n 7-guanine DNA-DNA cross-links in white blood cells of cancer patients receiving cyclophosphamide therapy. Anal Chem 82(9): 3650-3658.

64. Bauknecht T, Vogel W, Bayer U, Wild D (1977) Comparative in vivo mutagenicity testing by SCE and micronucleus induction in mouse bone marrow. Hum Genet 35(3): 299-307.

65. Goetz R, Sram RJ, Dohnalova J (1975) Relationship between experimental results in mammals and man. I. Cytogenetic analysis of bone marrow injury induced by a single dose of cyclophosphamide. Mutat Res 1(4): 247-254.

66. Vanderkerken K, Vanparys P, Verschaeve L, Kirsch Volders M (1989) The mouse bone marrow micronucleus assay can be used to distinguish aneugens from clastogens. Mutagenesis 4(1): 6-11.

67. Dobrzynska MM, Gajewski AK (1999) Induction of micronuclei in mouse bone marrow after combined X-rays-cyclophosphamide and X-rays-mitomycin C treatments. Teratog Carcinog Mutagen 19(4): $267-$ 274.

68. Dobrzynska MM (2000) Micronucleus formation induced by the combination of low doses of X-rays and antineoplastic drugs in bone marrow of male mice. Teratog Carcinog Mutagen 20(6): 321-327.

69. Johnson LA, Tretyakova N, Jacobson PA (2012) Obesity effects on cyclophosphamide-induced DNA damage in hematopoietic cell transplant recipients. In vivo 26(5): 853-857.

70. Gore PR, Prajapati CP, Mahajan UB, Goyal SN, Belemkar S, et al. (2016) Protective effect of thymoquinone against cyclophosphamide-induced hemorrhagic cystitis through inhibiting DNA Damage and upregulation of Nrf2 expression. Int J Biol Sci 12(8): 944-953.

\begin{tabular}{|l|}
\hline \multicolumn{1}{|c|}{ Your next submission with Juniper Publishers } \\
will reach you the below assets \\
- Quality Editorial service \\
- Swift Peer Review \\
- Reprints availability \\
- E-prints Service \\
- Manuscript Podcast for convenient understanding \\
- Global attainment for your research \\
- Manuscript accessibility in different formats \\
( Pdf, E-pub, Full Text, Audio) \\
- Unceasing customer service \\
Track the below URL for one-step submission \\
https://juniperpublishers.com/online-submission.php
\end{tabular}

